encouraged by the unofficial attitude of some of its members. Following last week's hearing Chairman Arthur Palmer openly admitted on British television that he was optimistic that the first part of the project could be completed and producing electricity within ten years.

\section{New president for Royal Society}

LORD Todd has been elected President of the Royal Society for the next five years; he succeeds Sir Alan Hodgkin, president since 1970. The new president is 68 , and is not entirely new to the office-his father-in-law, Sir Henry Dale, was president of the society from 1940-45.

The long list of positions he has held and honours he has received includes periods of research or lecturing at Glasgow, Frankfurt, Oxford, Edinburgh, London, Caltech, Manchester, Chicago, Sydney, MIT, and (since 1944) Cambridge. It also includes the Nobel Prize for Chemistry in 1957. From 1952-64, he was Chairman of the Advisory Council on Scientific Policy, and he was President of the International Union of Pure and Applied Chemistry from 1963 to 1965.

Sir Alan, in his retiring address, was critical of the government for its failure to appoint a chief scientific adviser to the Cabinet. "The need for central coordination", he said, "would become acute if the country were faced with a sudden crisis involving science and technology ... the Government would have to deal with a number of awkward questions ... . which did not fit easily into the remit of one research council or ministry . . . the chief scientific adviser would know his way round Whitehall, and he would know how to get the best scientists to work, both inside and outside Whitehall." The post of Chief Scientific Adviser has been vacant since Sir Alan Cottrell returned to academic life more than a year ago.

\section{Reforms suggested for French Academy}

\section{from the staff of La Recherche}

A report on the French Academie des Sciences, completed in the summer but so far not made public, has made recommendations which have already given rise to some controversy and criticism, particularly from the present academicians.

The report, from a small committee headed by P. Aigrain which was asked earlier this year by President Giscard d'Estaing to study principles and methods of reform, consists of a series of suggestions aimed at giving the Academy a more important role and one similar to that of some other national academies.

The report says that reform of the Academy must begin with lowering the average age of members, which is currently 72 . The committee studying ways and means has proposed that, on attaining the age of 70 , academicians should be invited to take an "emeritus" position, and retire with a pension. The number of academicians should also be gradually increased, over a period of three years, to 175 . The number of "corresponding members" would be raised to about 400 , and of foreign "associate members" to about 50. This increase in the number of academicians would pose a serious problem, however, in that, if spread over only three years, it would necessitate 25 to 30 elections per year.

The Aigrain report also recommends the reorganisation of the present inadequate divisions within the Academy. It advocates the creation of two divisions, with mathematics and physical sciences grouped together, and a second group combining chemistry, the life sciences and maybe the social sciences. A fixed percentage of academicians' seats would be reserved for representatives of the applied sciences.

Other less drastic measures are also proposed: an increase in the next budget of the Academy to give it real autonomy; the election of a president every three years, with the option to renew the term of office (the current term is one year); and the creation of posts for foreign researchers invited by the Academy to spend some time in France as "Academy Professors".

Although many of the present members of the Academy think the reforms suggested are too stringent, particularly the proposals to bring in more young blood, and although they oppose the Aigrain report, the Academy's place in French society has not always remained unquestioned. Founded in 1666 on the initiative of Colbert, it played a major part in French science for more than a century. The academicians with their pensions were in some ways the first professional researchers. Instructed by the government to carry out various scientific and technical studies, they did on occasions provide a real scientific advisory service.

The Academy's influence subsequently waned, and governments since 1945 have built new mechanisms for scientific policy which have effectively removed the Academy from decisionmaking centres and have caused the French scientific community to question its capacity to represent them.

The Minister for Industry and Re- search and the Secretary for State responsible for the universities must now decide on which measures to adopt. They will doubtless give in on one point at least, that the lowering of the age range could be spread over five years instead of three. However, since the Academy has elected a relatively young man, Professor $P$. Germain, to the post of Permanent Secretary, to replace L. de Broglie on his resignation, it appears that, even if with rather bad grace, the Academy is ready to accept a large part of the proposed reform.

Occasionally the animal kingdom seems to decide on its own to fight back against the manifestations of modern civilisation. In northern Israel recently, Syrian woodpeckers actually destroyed kibbutz irrigation systems. Apparently, they find the sound of water rushing through plastic irrigation pipes similar to the sound made by various insects inside trees, and so peck away at the plastic as if it were wood. Because the woodpeckers did not stop after failing to discover any insects, people are wondering whether the birds have developed a taste for plastics. Although distressing for the farmers, the development has at least shown that traditional plastics may be biodegradable after all.

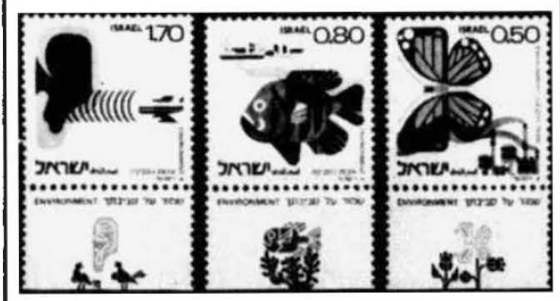

\section{Stamping out pollution}

Israel's environmental problems are particularly severe because of a decades-long tendency to disregard ecological considerations in an attempt to achieve rapid development at almost any cost. This now seems to be changing, if the establishment of several bodies to deal with environmental deterioration is anything to go by. A series of stamps (above) has also been issued on the subject. They deal with air pollution (a butterfly engulfed by factory fumes), water pollution (a fish swimming in waste discharged by a ship) and noise pollution (an ear, presumably human, under assault by sound waves from a jet). Tabs below the stamps show the butterfly in the company of flowers rather than fumes, the fish next to an underwater plant rather than a ship, and an ear serenaded by birds rather than jets.

from Nechemia Meyers 